\title{
VARIABILIDADE DO SISTEMA CORRENTE DO BRASIL ASSOCIADA AOS CENÁRIOS DE MUDANÇAS CLIMÁTICAS A1FI E B1
}

\author{
BÖCK, C.S. ${ }^{1 *}$; ASSAD, L.P.F. ${ }^{2} \&$ LANDAU, L. $^{3}$ \\ 1. Laboratório de Métodos Computacionais em Engenharia, Programa de Engenharia Civil, Universi- \\ dade Federal do Rio de Janeiro - COPPE, RJ, Brasil \\ 2. Departamento de Meteorologia, Instituto de Geociências, Universidade Federal do Rio de Janeiro, \\ RJ, Brasil \\ 3. Laboratório de Métodos Computacionais em Engenharia, Programa de Engenharia Civil, Universi- \\ dade Federal do Rio de Janeiro - COPPE, RJ, Brasil \\ *Corresponding author: bock@lamce.coppe.ufrj.br
}

\begin{abstract}
Böck, C.S.; Assad, L.P.F. \& Landau, L., (2015). Variabilidade do sistema corrente do Brasil associada aos cenários de mudanças climáticas A1FI e B1. Braz. J. Aquat. Sci. Technol. 19(3). elSSN 1983-9057. DOI: 10.14210/bjast.v19n3. The aim of this work is to investigate the behavior of volume transport and advective heat flux patterns, which are related to the Brazil Current System (BCS) according to the climate change scenarios suggested by the Intergovernmental Panel on Climate Changes (IPCC). The results were derived from the global model Climate Model version 2.1 (GFDL-CM2.1) for future scenarios of climate change A1FI and B1 and for the scenario that represents the climate in the Twentieth Century $(20 \mathrm{C} 3 \mathrm{M})$. Volume transport and advective heat flux were integrated for the whole BCS as well as for each water mass which constituting the system, and were calculated applying this data. Estimates were made for three zonal sections $\left(23^{\circ} \mathrm{S}\right.$, $25^{\circ} \mathrm{S}$ and $30^{\circ} \mathrm{S}$ ) and afterwards were used in the Wavelet Analysis. The performed analysis showed the occurrence of interannual variability for the estimated properties in the region. It also demonstrated that the BCS shows changes in both intensity and variability of these parameters when comparing A1FI and B1 to 20C3M. Results from Wavelet Analysis for the total volume transport and integrated sectional advective heat flux show that the period between three and six years prevailed in sections $23^{\circ} \mathrm{S}$ and $25^{\circ} \mathrm{S}$. The variability in $30^{\circ} \mathrm{S}$ however, was significantly higher than eight years. The change in variability of the total volume transport and heat flux temporal series towards higher frequencies was observed when they were subjected to $\mathrm{A} 1 \mathrm{FI}$ and $\mathrm{B} 1$ climate change scenarios.
\end{abstract}

Keywords: South Atlantic ocean, Brazil current system, IPCC, GFDL-CM2.1, Wavelet analysis.

\section{INTRODUÇÃO}

Desde a sua criação, o Intergovernmental Panel on Climate Changes (IPCC) se tornou a principal referência em produção de estudos sobre as mudanças climáticas globais, tema este que têm sido o centro de debates científicos durante o século XXI, despertando grande interesse da sociedade.

Uma das principais metodologias usadas pelo IPCC para entender o sistema climático e as causas e os efeitos das mudanças climáticas inclui simulações através de modelos numéricos climáticos forçados por cenários futuros de emissão. Os resultados de tais simulações representariam a resposta do clima às alterações nas concentrações de gases de efeito estufa e aerossóis. Por isso, desde sua publicação pelo IPCC, os cenários de emissão SRES (Special Report on Emissions Scenarios) tornaram-se parte crucial nas pesquisas sobre mudanças do clima (IPCC, 2000).

Considerando o acoplamento oceano-atmosfera, é de se esperar que mudanças climáticas de grande escala, resultantes da mudança nas concentrações dos gases do efeito estufa, tenham profundo impacto nos padrões de circulação oceânica (Marengo, 2007). Assim, estudos sobre parâmetros oceanográficos e climáticos regionais podem revelar tendências que são fundamentais para estudos de mudanças climáticas globais, já que as interações entre o oceano e a atmosfera são a chave para conhecer e prognosticar o clima e suas variações (Kushnir et al., 2002).

A dinâmica e a variabilidade de parâmetros oceanográficos em escalas interanuais no Oceano Atlântico Sul ainda não são bem compreendidas e muito sobre o comportamento de suas feições permanece desconhecido (Wainer \& Venegas, 2002; Lumpkin \& Garzoli, 2011), em particular referente à sensibilidade do Atlântico Sul e de suas correntes aos cenários de mudanças climáticas.

Sendo assim, o objetivo do trabalho é investigar o comportamento dos padrões dos transportes de volume e fluxos de calor associados ao Sistema Corrente do Brasil frente aos cenários de mudanças climáticas SRES A1FI e B1 propostos pelo IPCC.

\section{O Sistema Corrente do Brasil}

A Corrente do Brasil (CB), uma das principais correntes associadas ao Giro Subtropical do Atlântico Sul, se origina à sul de $10^{\circ} \mathrm{S}$, próximo à região da bifurcação da Corrente Sul Equatorial (CSE), flui para sul 
se estendendo ao longo das plataformas continentais do Brasil, do Uruguai e da Argentina até aproximadamente a latitude $38^{\circ} \mathrm{S}$, onde forma a confluência com a Corrente das Malvinas (CM) (Peterson \& Stramma, 1991). Em função da complexidade do escoamento associada à $\mathrm{CB}$, na literatura científica a dinâmica da CB é muitas vezes associada ao termo "Sistema
Corrente do Brasil" (SCB) (Godói, 2005; Silveira, 2007). Este termo engloba a CB, que transporta Água Tropical (AT) e Água Central do Atlântico Sul (ACAS), seus meandros e vórtices e a Corrente de Contorno Intermediária ( $\mathrm{CCl}$ ), que em níveis picnoclínicos flui em sentido oposto à CB e transporta Água Intermediária Antártica (AIA) (Figura 1).

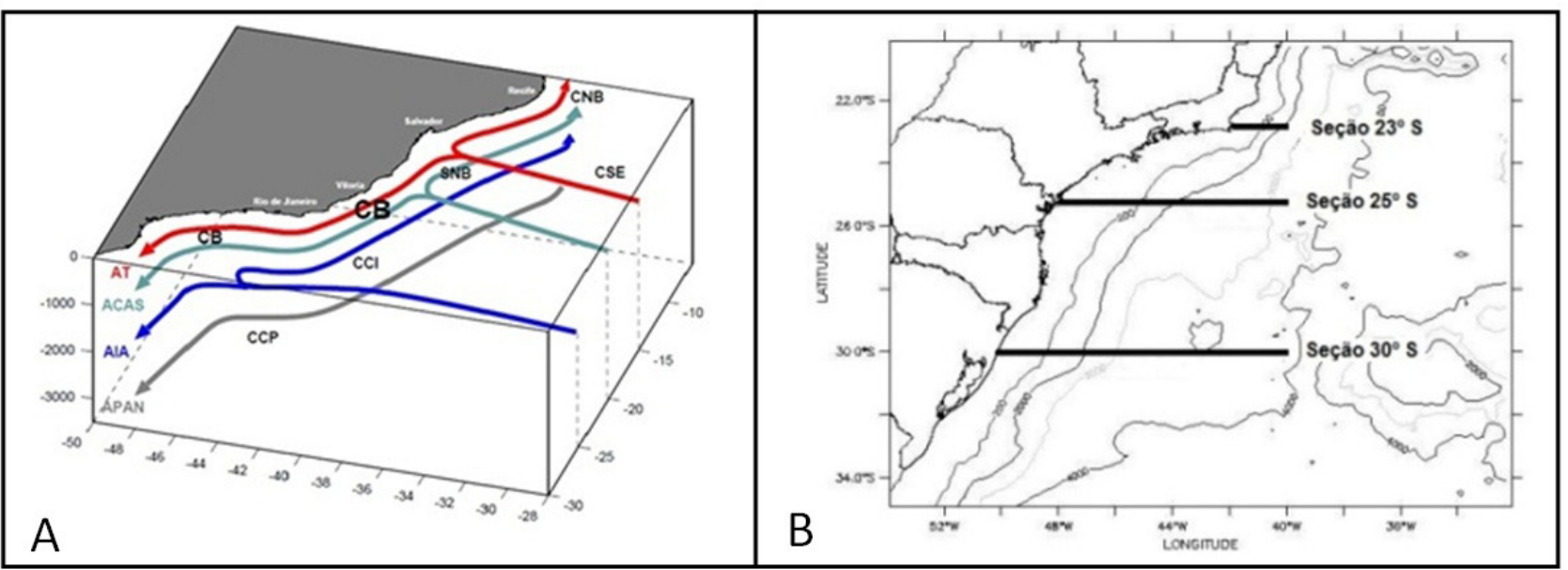

Figura 1 - Em A) esquematização, conforme Stramma \& England (1999), do escoamento do sistema de correntes de contorno oeste do Oceano Atlântico Sul (Soutelino, 2008. Em B) posicionamento das seções analisadas.

Estudos relevantes sobre as características oceanográficas da $\mathrm{CB}$, especialmente relacionados à estimativa de transporte de volume, incluem Evans et al. (1983), Evans \& Signorini (1985), Stramma (1989), Stramma et al. (1990), Campos et al. (1995) e Müller et al. (1998).

A maioria das estimativas de transporte de volume da $\mathrm{CB}$ foi feita na plataforma continental e ao largo do Rio de Janeiro, próximo à Cabo Frio, e na Confluência Brasil-Malvinas (CBM) e grande parte dos resultados provém de cálculos geostróficos a partir de dados coletados em cruzeiros hidrográficos (Silveira, 2007). O transporte da CB varia com a latitude; ao longo de seu percurso, tornando-se mais profunda e com transporte mais intensificado em direção sul (Müller et al., 1998), alcançando valores próximos à $30 \mathrm{~Sv}$, a maioria deles tipicamente confinados em profundidades menores que 1000m (Garzoli, 1993).

Segundo Peterson \& Stramma (1991), ao norte de $25^{\circ} \mathrm{S}$ a CB é uma corrente fraca, com um transporte estimado inferior à $11 \mathrm{~Sv}$. Ao sul de $25^{\circ} \mathrm{S}$, o transporte da CB aumenta a uma taxa de $5 \%$ por $100 \mathrm{~km}$ (Gordon \& Greengove, 1986). Ao sul de aproximadamente $30^{\circ} \mathrm{S}$, o aumento do transporte parece estar relacionado à presença da célula de recirculação anticiclônica (Olson et al., 1988) que apresenta transporte geostrófico de aproximadamente $7,5 \mathrm{~Sv}$ nos primeiros $800 \mathrm{~m}$ (Stramma, 1989), fazendo com que o transporte da CB próximo à $33^{\circ} \mathrm{S}$ seja de aproximadamente $18 \mathrm{~Sv}$ (Peterson \& Stramma, 1991).
Numerosos estudos têm sido realizados para a determinação do transporte de calor no oceano global, seja através de observações diretas, modelos inversos ou modelos numéricos. Garzoli \& Baringer (2007) analisaram dados de temperatura coletados entre 2002 e 2006 em 14 seções posicionadas entre Buenos Aires (Argentina) e a Cidade do Cabo (África do Sul). Os valores obtidos para o transporte de calor meridional total associado às seções, integrado da superfície à $800 \mathrm{~m}$ de profundidade, variaram entre 0,40 e 0,81PW, com valor médio de 0,54PW e desvio padrão de 0,11PW (Garzoli \& Baringer, 2007). Assad (2006), através de modelagem numérica, estimou o transporte de calor médio integrado até o fundo oceânico para uma seção zonal em $32^{\circ} \mathrm{S}$, ao longo de toda a extensão da bacia do Atlântico Sul, em 0,60PW $( \pm 0,02)$, sendo que foi observada uma intensificação do transporte de calor nos meses de Junho, Julho e Setembro nesta seção.

Estimativas de transporte de calor especificamente para a CB se resumem ao trabalho de Vianna (2012), que a partir de 44 anos de resultados da reanálise oceânica Simple Ocean Data Assimilation (SODA) determinou o fluxo advectivo de calor em três seções zonais no Atlântico Sul, delimitadas a oeste pela linha de costa e a leste pelo limite da Plataforma Continental Brasileira, obtendo valores médios de $-0,12 \mathrm{PW}( \pm 0,29)$ na seção em $23^{\circ} \mathrm{S},-0,23 \mathrm{PW}( \pm 0,27)$ em $25^{\circ} \mathrm{S}$ e $-0,92 \mathrm{PW}( \pm 0,33)$ em $30^{\circ} \mathrm{S}$.

O regime do Atlântico Sudoeste em várias es- 
calas de variabilidade no tempo têm sido objeto de estudo de diversas investigações, tais como Stramma \& Scott (1999), Stramma et al. (2005) e Schott et al. (2005), porém, poucos trabalhos na literatura tratam especificamente sobre a variabilidade da CB.

Diante das observações de que a latitude onde ocorre a CBM varia sazonalmente, estando mais ao norte durante o inverno austral (Julho à Setembro) do que durante o verão austral (Janeiro à Março), Peterson \& Stramma (1991) relacionaram a sazonalidade na posição da CBM à sazonalidade na mudança do regime de ventos e a mudança meridional sazonal do Giro Subtropical. Matano et al. (1993) investigaram a hipótese de que esta oscilação estivesse relacionada à variação sazonal no transporte de massa de cada uma das correntes. Através da modelagem numérica e de dados altimétricos oriundos de sensores fixos a plataformas orbitais, puderam constatar que durante $o$ verão austral, há um aumento no transporte de massa da CB ao mesmo tempo em que há uma diminuição do transporte da $\mathrm{CM}$, o que causa um deslocamento da posição da CBM mais para sul. A situação oposta é observada no inverno.

Lumpkin \& Garzoli (2011), investigando a variabilidade interanual à interdecadal na circulação de superfície do Atlântico Sudoeste, especialmente na região da CBM, constataram que acima de $30 \mathrm{~m}$ de profundidade, o transporte de superfície associado à CB sofre variabilidade sazonal e interanual na série de dados analisados (de 1993 à 2007), entretanto não foram observadas tendências à variabilidade de longo prazo na $\mathrm{CB}$, por exemplo, multidecadais, que só foram observadas na região da CBM.

Além da variabilidade sazonal, uma variabilidade interanual significativa no transporte da CB e na posição da CBM tem sido observada (Garzoli, 1993; Wainer \& Venegas, 2002). Ao contrário da variabilidade sazonal, que é controlada pelo ciclo sazonal do rotacional da tensão de cisalhamento do vento no Atlântico Sul Subtropical (Matano et al., 1993), a variabilidade interanual seria forçada por um campo de vento anômalo ao sul da região da confluência (Garzoli \& Giulivi, 1994). As mudanças na posição da confluência, por sua vez, impactam a atmosfera com prováveis efeitos sobre a ciclogênese e sobre a distribuição regional de chuvas (Wainer \& Venegas, 2002).

A variabilidade espaço-temporal dos processos oceânicos pode estar associada a fenômenos locais à região, tais como apresentados anteriormente, ou de origem remota. Assad (2006) se dedicou a investigar, através da modelagem numérica, como a dinâmica de setores do Atlântico Sul pode responder às alterações atmosféricas associadas ao campo de vento superficial durante um evento El- Niño/Oscilação Sul (ENOS). No Atlântico Sul, o autor observou que anomalias atmosféricas globais, associadas ao campo de pseudotensão de cisalhamento do vento do tipo ENOS, causaram aceleração do transporte de volume associado ao Giro Subtropical e aumento do transporte de calor meridional para norte. Em superfície, observou o aparecimento de anomalias de temperatura potencial na bacia sudoeste do Atlântico Sul associado à intensificação dos transportes da CB.

Quanto aos padrões do fluxo de calor, Garzoli \& Baringer (2007) afirmam que grande parte da variabilidade no transporte de calor pode ser uma característica da circulação do Atlântico Sul devido, em parte, à grande variabilidade das correntes de contorno, já que ambas as margens são caracterizadas como regiões altamente energéticas e variáveis (Garzoli \& Baringer, 2007).

Cabe ressaltar a escassez de literatura referente à compreensão da variabilidade da CB entre as latitudes de $23^{\circ} \mathrm{S}$ e $30^{\circ} \mathrm{S}$, especialmente quando tratamos de seu comportamento associado aos cenários de mudanças climáticas. A maioria dos estudos, conforme apresentado nos tópicos anteriores, analisam o comportamento e a variabilidade da CB próximo a bifurcação da CSE e próximo à CBM.

\section{MATERIAL E MÉTODOS}

Resultados oceânicos obtidos de um modelo global climático acoplado (oceano, atmosfera, superfície terrestre e gelo) foram utilizados para caracterizar a circulação do SCB no clima presente e sob a influência de cenários futuros de mudanças climáticas. Com estes resultados, para analisar a variabilidade do SCB, foram estimadas propriedades dinâmicas e termodinâmicas. Foi calculado o transporte de volume e o fluxo advectivo de calor mensais em cada seção e em cada massa d'água analisada. AAnálise de Ondaletas foi utilizada para avaliar a variabilidade interanual das séries temporais de transporte de volume e de fluxo advectivo de calor. Todas as etapas são especificadas nos próximos tópicos.

\section{Seções Zonais e Massas D’Água Analisadas}

Devido à extensão do SCB, foram escolhidas três seções zonais a partir das quais foram feitas as análises propostas no trabalho. A primeira seção é localizada em $23^{\circ} \mathrm{S}$, a segunda em $25^{\circ} \mathrm{S}$ e a terceira em $30^{\circ} \mathrm{S}$ (Figura 1). As seções são limitadas à oeste pela linha de costa e à leste pela longitude $40^{\circ} \mathrm{W}$. A escolha das seções foi baseada na disponibilidade de alguns dados observacionais e estimativas de transporte nestas regiões na literatura.

Considerando que AT, ACAS e AIA são transportadas pelo SCB, os valores considerados no 
presente trabalho das superfícies isopicnais $\left(\sigma_{0}\right)$ que representam as interfaces entre as massas de água do Oceano Atlântico Sul, na região do Giro Subtropical, foram extraídos de Mémery et al. (2000). Sendo assim, AT é definida por $\sigma_{0} \leq 25,60 \mathrm{~kg} \cdot \mathrm{m}^{-3}$, ACAS é delimitada por $25,60 \mathrm{~kg} \cdot \mathrm{m}^{-3}<\sigma_{0} \leq 26,90 \mathrm{~kg} \cdot \mathrm{m}^{-3}$ e AIA por $26,90 \mathrm{~kg} \cdot \mathrm{m}^{-3}<\sigma_{0} \leq 27,38 \mathrm{~kg} \cdot \mathrm{m}^{-3}$.

\section{O Modelo GFDL-CM2.1}

Para as três seções, foram adquiridos valores mensais de velocidade zonal, velocidade meridional, temperatura do mar e salinidade gerados pelo modelo climático Climate Model version 2.1 (CM2.1), desenvolvido pelo Geophysical Fluid Dynamics Laboratory do National Oceanic and Atmospheric Administration. Esse foi um dos modelos utilizados para realizar uma série de simulações climáticas para o Quarto Relatório Científico (Fourth Assessment Report - AR4) do IPCC. Ele é composto de quatro componentes que simulam a terra/biosfera, a criosfera, a atmosfera e o oceano, sendo que a componente oceânica (OM3.1) possui resolução horizontal de $1^{\circ}$ de latitude e longitude, diminuindo meridionalmente em direção aos trópicos e 50 níveis verticais com 22 níveis equi-espaçados $(10 \mathrm{~m})$ nos primeiros $220 \mathrm{~m}$ de coluna d'água. O resultado final do GFDL-CM2.1 é disponibilizado com resolução espacial de 200 pontos de latitude, 360 de longitude e 50 níveis verticais para o oceano, e as variáveis prognósticas são as componentes zonal e meridional da velocidade, altura no nível do mar, temperatura e salinidade. Informações sobre suas componentes e o sistema de acoplamento podem ser obtidos em Delworth et al. (2006).

\section{Cenários Controle e de Mudanças Climáticas}

Para caracterizar a circulação do SCB no clima presente e sob a influência de cenários futuros de mudanças climáticas, os resultados oceânicos obtidos do CM2.1 foram provenientes das simulações dos cenários SRES A1FI e B1 e do cenário 20C3M. $O$ cenário $A 1 \mathrm{FI}$ é um cenário que assume elevadas emissões de gases de efeito estufa, em função do intensivo uso de combustível fóssil e o B1 é um cenário que descreve baixas emissões atmosféricas de gases do efeito estufa, com a estabilização da concentração de gás carbônico em 550ppm (IPCC, 2000). A1FI e B1 simulam o período compreendido entre os anos de 2001 e 2100 . O cenário controle 20C3M simula o clima no século XX, entre os anos de 1901 e 2000 (IPCC, 2000).

\section{Estimativas de Transporte de Volume e Fluxo Advectivo de Calor}

Com estes resultados, para analisar a variabilidade do SCB, foi calculado, mensalmente para cada seção, o transporte de volume do SCB como um todo e individualmente para as camadas referentes às massas d'água citadas, segundo a equação:

$$
H v=\int_{0}^{L} \int_{-h(x)}^{0} v(x, z, t) d z d x \text {, onde } H v \text { é o trans- }
$$
porte de volume, $v$ é a componente meridional da velocidade, $L$ é a largura da seção e $-h(x)$ é a profundidade e corresponde aos níveis isopicnais pré-definidos e relativos à AT, ACAS e AIA.

Adicionalmente foi determinado o fluxo advectivo de calor do SCB como um todo e para cada massa d'água, mensalmente para cada seção, segundo a equação:

$$
Q=\rho C_{p} \int_{0}^{L} \int_{-h(x)}^{0} v \theta d z d x \text {, onde Q é o fluxo }
$$
advectivo de calor, $\rho$ é a densidade da água do mar, $C_{p}$ é o calor específico da água do mar, $\theta$ é a temperatura potencial, $v$ é a componente meridional da velocidade, $x$ é a dimensão horizontal e $z$ é a dimensão vertical.

\section{Análise de Ondaletas}

Visando identificar os padrões de variabilidade temporal (interanual, interdecadal) das séries de transporte de volume e fluxo de calor do SCB, foi utilizada a análise ou técnica de Ondaletas (Lau \& Weng, 1995; Torrence \& Compo, 1998), cujo princípio central consiste em decompor uma série temporal em diferentes níveis de resolução tempo-freqüência e então determinar as componentes da variabilidade dominantes e o período nas quais ocorrem.

Para a análise de ondaletas, foram utilizadas as séries temporais do fluxo de calor total integrado em cada seção e o transporte de volume total integrado em cada seção para cada cenário. Para as análises espectrais apresentadas neste estudo foi utilizada a ondaleta de Morlet (Morlet, 1983), frequentemente utilizada em trabalhos com séries temporais de dados oceanográficos e atmosféricos, já que possui características semelhantes às destes sinais, tais como simetria ou assimetria e variação temporal brusca ou suave (Lau \& Weng, 1995; Torrence \& Compo, 1998).

\section{Estudo de Eventos Selecionados}

A partir dos resultados da Análise de Ondaletas, foi identificado o ano correspondente à maior energia das séries temporais nos cenários $\mathrm{A} 1 \mathrm{FI}$ e $\mathrm{B} 1$. Em cada um destes anos foram calculados o transporte de volume e o fluxo de calor integrados totais médios e os transportes e fluxos integrados das camadas correspondentes à AT, ACAS e AIA médios. Tais valores foram comparados aos transportes e fluxos médios do cenário 20C3M no período entre 1901 e 2000. 


\section{RESULTADOS}

\section{Transporte de Volume e Fluxo Advectivo de Calor}

Os valores médios das séries temporais mensais do transporte de volume e do fluxo advectivo de calor totais integrados por seção e para as camadas referentes às massas d'água AT, ACAS e AIA em todos os cenários são apresentados na tabela I. Os valores positivos indicam transporte ou fluxo para norte e os valores negativos indicam transporte ou fluxo para sul. Considerando os transportes e os fluxos totais do SCB, o maior transporte de volume médio foi $-6,56 \mathrm{~Sv}( \pm 1,41)$ na seção $30^{\circ} \mathrm{S}$ e cenário $\mathrm{B} 1$, enquanto o menor transporte médio foi $-0,35 \mathrm{~Sv}( \pm 0,37)$ na seção $23^{\circ} \mathrm{S}$ no cenário $20 \mathrm{C} 3 \mathrm{M}$. Quanto ao fluxo de calor, o maior fluxo de calor médio foi $-359,19.10^{-3} \mathrm{PW}$ $\left( \pm 87,43.10^{-3}\right)$ na seção $30^{\circ} S$ e cenário $B 1$, enquanto o menor fluxo médio foi $-52,21.10^{-3} \mathrm{PW}\left( \pm 22,08.10^{-3}\right)$ na seção $23^{\circ} \mathrm{S}$ no cenário $\mathrm{A} 1 \mathrm{FI}$.

Tabela I - Transportes de volume médios (Sv) e fluxos advectivos de calor médios (.10-3PW) totais e das camadas referentes à AT, ACAS e AIA nas seções $23^{\circ} \mathrm{S}, 25^{\circ} \mathrm{S}$ e $30^{\circ} \mathrm{S}$ em todos os cenários e seus respectivos desvios padrão.

\begin{tabular}{|c|c|c|c|c|c|c|c|c|c|}
\hline \multicolumn{2}{|c|}{$\begin{array}{c}\text { Transporte de } \\
\text { Volume (Sv) }\end{array}$} & \multirow{2}{*}{$\begin{array}{c}20 \mathrm{C} 3 \mathrm{M} \\
-0,35 \pm 0,37\end{array}$} & \multirow{2}{*}{$\begin{array}{c}\text { A1FI } \\
-0,38 \pm 0,37\end{array}$} & \multirow{2}{*}{$\begin{array}{c}\text { B1 } \\
-0,53 \pm 0,40\end{array}$} & \multicolumn{2}{|c|}{$\begin{array}{c}\text { Fluxo de Calor } \\
\left(.10^{-3} \mathrm{PW}\right)\end{array}$} & \multirow{2}{*}{$\begin{array}{c}\text { 20С3M } \\
-54,36 \pm 20,39\end{array}$} & \multirow{2}{*}{$\begin{array}{c}\text { A1FI } \\
-52,21 \pm 22,08\end{array}$} & B1 \\
\hline \multirow{4}{*}{$\begin{array}{c}23^{\circ} \\
S\end{array}$} & Total & & & & \multirow{4}{*}{$\begin{array}{c}23^{\circ} \\
S\end{array}$} & Total & & & $-59,38 \pm 22,76$ \\
\hline & AT & $-0,40 \pm 0,11$ & $-0,49 \pm 0,15$ & $-0,47 \pm 0,13$ & & AT & $-36,17 \pm 9,95$ & $-45,07 \pm 13,57$ & $-42,78 \pm 12,11$ \\
\hline & ACAS & $-0,26 \pm 0,21$ & $-0,05 \pm 0,26$ & $-0,21 \pm 0,22$ & & ACAS & $-25,43 \pm 11,23$ & $-11,33 \pm 14,49$ & $-20,59 \pm 11,88$ \\
\hline & AIA & $0,31 \pm 0,12$ & $0,16 \pm 0,15$ & $0,15 \pm 0,15$ & & AIA & $7,24 \pm 2,81$ & $4,20 \pm 3,88$ & $3,99 \pm 3,75$ \\
\hline \multirow{4}{*}{$\begin{array}{c}25^{\circ} \\
\mathrm{S}\end{array}$} & Total & $-1,85 \pm 1,35$ & $-2,29 \pm 1,41$ & $-2,73 \pm 1,51$ & \multirow{4}{*}{$\begin{array}{l}25^{\circ} \\
\mathrm{S}\end{array}$} & Total & $-208,91 \pm 73,19$ & $-216,67 \pm 81,70$ & $-237,27 \pm 84,06$ \\
\hline & AT & $-1,22 \pm 0,30$ & $-1,47 \pm 0,48$ & $-1,34 \pm 0,36$ & & AT & $-110,80 \pm 27,34$ & $-137,06 \pm 44,87$ & $-124,45 \pm 33,11$ \\
\hline & ACAS & $-1,49 \pm 0,85$ & $-1,11 \pm 0,86$ & $-1,64 \pm 0,86$ & & ACAS & $-117,21 \pm 47,73$ & $-87,02 \pm 51,15$ & $-119,14 \pm 49,06$ \\
\hline & AIA & $0,85 \pm 0,38$ & $0,30 \pm 0,47$ & $0,26 \pm 0,46$ & & AIA & $19,10 \pm 8,09$ & $7,41 \pm 12,09$ & $6,32 \pm 11,73$ \\
\hline \multirow{4}{*}{$\begin{array}{c}30^{\circ} \\
\mathrm{S}\end{array}$} & Total & $-5,34 \pm 1,18$ & $-6,20 \pm 1,29$ & $-6,56 \pm 1,41$ & \multirow{4}{*}{$\begin{array}{c}30^{\circ} \\
\mathrm{S}\end{array}$} & Total & $-260,24 \pm 68,77$ & $-358,19 \pm 87,96$ & $-359,19 \pm 87,43$ \\
\hline & AT & $-0,54 \pm 0,45$ & $-1,21 \pm 0,80$ & $-0,81 \pm 0,55$ & & AT & $-49,39 \pm 41,67$ & $-111,82 \pm 74,40$ & $-75,46 \pm 51,82$ \\
\hline & ACAS & $-3,09 \pm 0,85$ & $-3,75 \pm 0,85$ & $-4,31 \pm 1,02$ & & ACAS & $-174,15 \pm 55,58$ & $-216,60 \pm 55,89$ & $-249,48 \pm 66,94$ \\
\hline & AIA & $-1,72 \pm 0,50$ & $-1,23 \pm 0,40$ & $-1,42 \pm 0,41$ & & AIA & $-36,70 \pm 10,91$ & $-29,76 \pm 9,50$ & $-34,25 \pm 10,73$ \\
\hline
\end{tabular}

Os transportes de volume integrados (totais) médios aumentaram tanto em $\mathrm{A} 1 \mathrm{FI}$ quanto em $\mathrm{B} 1$, comparativamente à $20 \mathrm{C} 3 \mathrm{M}$, em todas as seções, sendo que $B 1$ exibe aumentos mais significativos do transporte médio do que A1FI. Considerando os resultados de fluxo de calor, com exceção do cenário A1FI na seção $23^{\circ} \mathrm{S}$, tanto $\mathrm{A} 1 \mathrm{FI}$ nas outras seções e B1 em todas as seções exibiram aumento no fluxo de calor integrado médio em relação ao cenário 20C3M. Os aumentos mais expressivos do fluxo de calor integrado médio foram observados na seção $30^{\circ} \mathrm{S}$.

Na seção $23^{\circ} \mathrm{S}$, em todos os cenários, a AT é responsável pela maior parte do transporte de volume do SCB. O transporte de volume médio da AT em todos os cenários é similar. Já os transportes de volume médios da ACAS e da AIA apresentam uma redução significativa nos cenários $\mathrm{A} 1 \mathrm{Fl}$ e B1 comparativamente ao cenário $20 \mathrm{C} 3 \mathrm{M}$.

Na seção $25^{\circ} \mathrm{S}$, a AT e a ACAS colaboram com a maior parte do transporte de volume do SCB e os transportes médios apresentados por ambas as massas são similares. Comparando-se aos resultados de 20C3M, o transporte de volume médio da AT aumenta em A1FI e B1, enquanto o transporte médio da ACAS é reduzido no cenário $\mathrm{A} 1 \mathrm{FI}$ e aumentado em $\mathrm{B} 1$.
Em $30^{\circ} \mathrm{S}$, a principal contribuição no transporte de volume total provém da ACAS nos três cenários. O transporte de volume médio da ACAS aumenta em A1FI e B1, sendo que este último cenário exibe a maior variação. O transporte médio da AT também aumenta nos cenários $\mathrm{A} 1 \mathrm{FI}$ e $\mathrm{B} 1$, porém o maior aumento é exibido pelo cenário $\mathrm{A} 1 \mathrm{FI}$. O transporte médio da AIA é reduzido tanto no cenário $A 1 \mathrm{FI}$ quanto no cenário $B 1$.

Nas seções $23^{\circ} \mathrm{S}$ e $25^{\circ} \mathrm{S}$, no cenário $20 \mathrm{C} 3 \mathrm{M}$, as contribuições da AT e ACAS ao fluxo de calor integrado total são semelhantes e juntas correspondem à maior parte do fluxo de calor integrado do SCB. Já na seção $30^{\circ} \mathrm{S}$, o fluxo de calor de ACAS predomina sobre o fluxo de calor da AT.

Por outro lado, no cenário $\mathrm{A} 1 \mathrm{FI}$ e $\mathrm{B} 1$, o fluxo de calor de AT predomina sobre o fluxo de calor de ACAS nas seções $23^{\circ} \mathrm{S}$ e $2^{\circ} \mathrm{S}$. Semelhante ao cenário $20 \mathrm{C} 3 \mathrm{M}$, em $30^{\circ} \mathrm{S}$ o fluxo de calor de ACAS predomina sobre o fluxo de calor exercido por AT em ambos os cenários.

Em todas as seções e cenários, AIA apresenta pequeno fluxo de calor médio em relação aos fluxos de AT e ACAS, sendo que sua contribuição ao fluxo de calor integrado total é maior em $30^{\circ} \mathrm{S}$. 


\section{Análise de Ondaletas}

As análises comparativas entre os resultados da técnica de Ondaleta para o transporte de volume e para o fluxo de calor totais integrados por seção revelam que, para um mesmo cenário, a variabilidade temporal das séries é muito similar (Tabela II). Sendo assim, optou-se por apresentar apenas as figuras referentes aos resultados da análise de ondaletas das séries temporais do transporte de volume.

Tabela II - Picos dominantes do Espectro Global de Ondaleta referentes às análises sobre o transporte de volume integrado e fluxo de calor integrado.

\begin{tabular}{ccccccccccc}
\hline $\begin{array}{c}1^{\circ} \text { e } 2^{\circ} \text { Períodos (em } \\
\begin{array}{c}\text { anos) de Maior } \\
\text { Energia }\end{array}\end{array}$ & 20C3M & A1FI & B1 & 20C3M & A1FI & B1 & 20C3M & A1FI & B1 \\
\hline $\begin{array}{c}\text { Transporte } \\
\text { de Volume }\end{array}$ & $1^{\circ}$ & 5 & 3 & 4 & 6 & 4 & 4 & 15 & 9 & 12 \\
Fluxo de & $1^{\circ}$ & 5 & 4 & 12 & 4 & 3 & 11 & 6 & 4 & 6 \\
Calor & $2^{\circ}$ & 3 & 3 & 4 & 6 & 4 & 4 & 15 & 8 & 12 \\
\hline
\end{tabular}

As figuras 2, 3 e 4 exibem o espectro de energia para a série de transporte de volume em cada cenário. A curva em forma de $U$ representa o cone de influência, sob o qual o efeito de borda é importante. As oscilações estão distribuídas em bandas entre um e 16 anos. Todas as séries apresentam diferentes periodicidades durante o período considerado. Os gráficos de energia global da ondaleta apontam para as maiores energias associadas às séries. O contorno tracejado indica que o espectro global da ondaleta é significativo ao nível de confiança de $95 \%$.

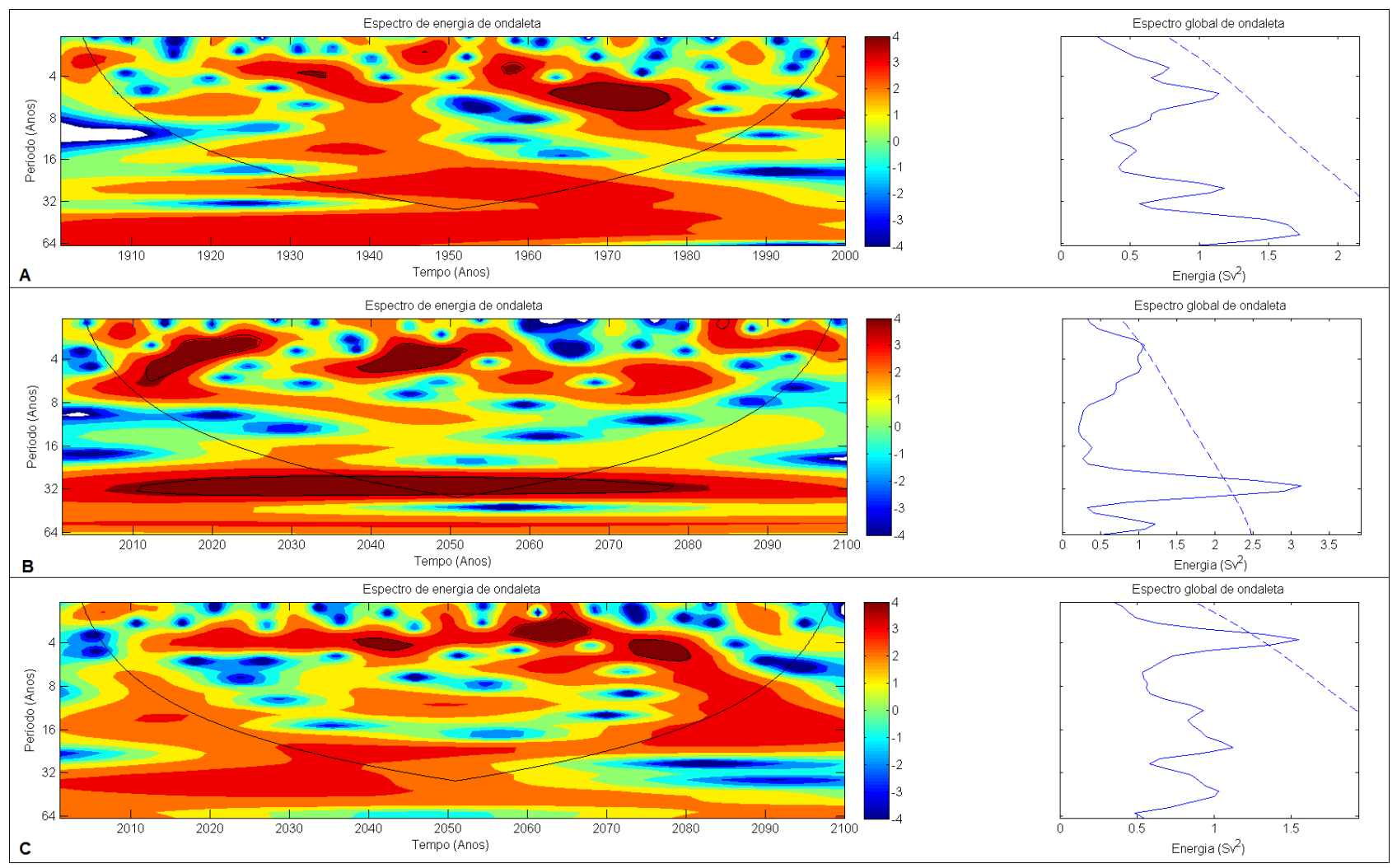

Figura 2 - Análise de ondaleta para o transporte de volume na seção $23^{\circ}$ S nos cenários A) 20C3M, B) A1FI e C) B1. 


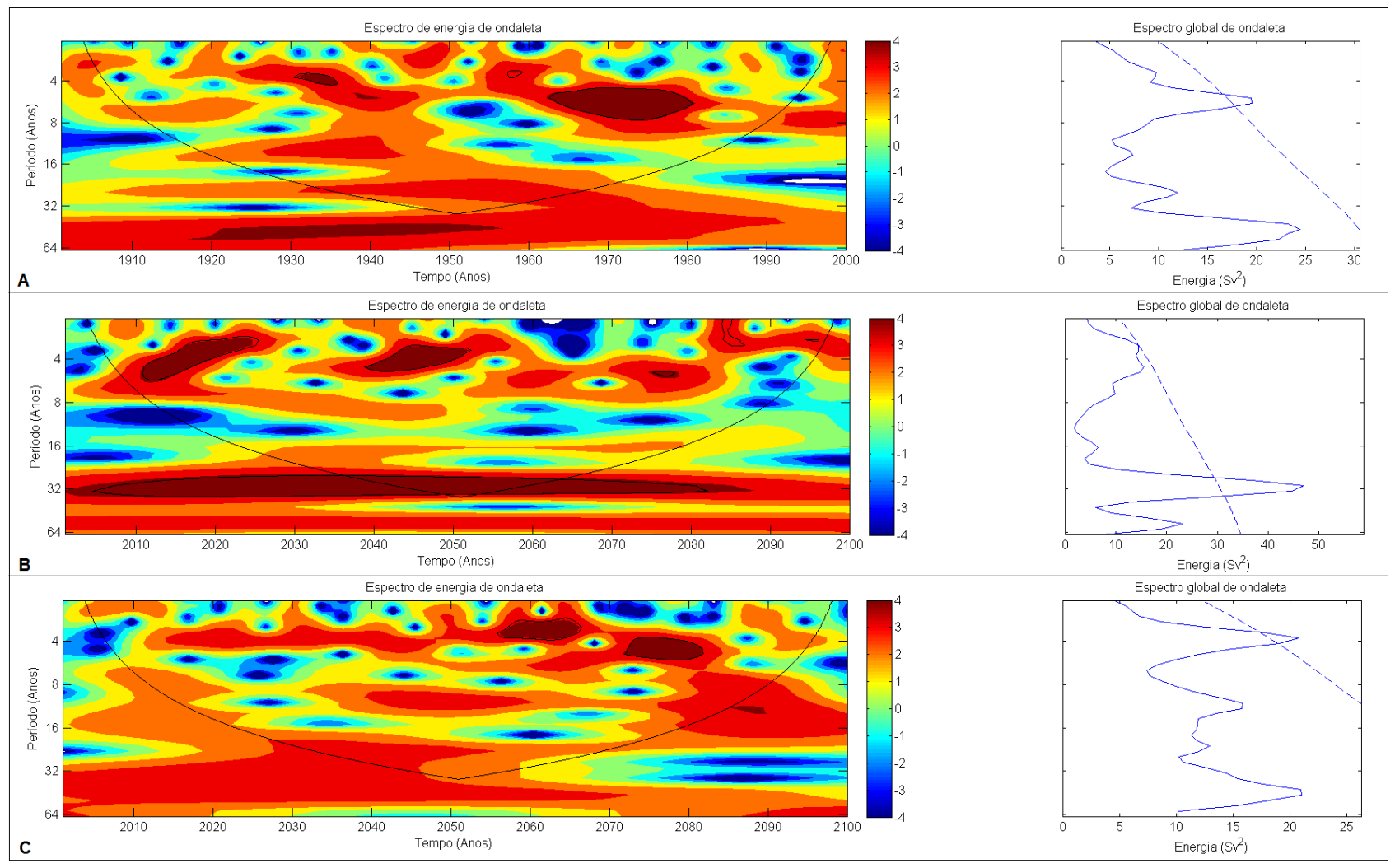

Figura 3 - Análise de ondaleta para o transporte de volume na seção $25^{\circ} S$ nos cenários A) 20C3M, B) A1FI e C) B1.

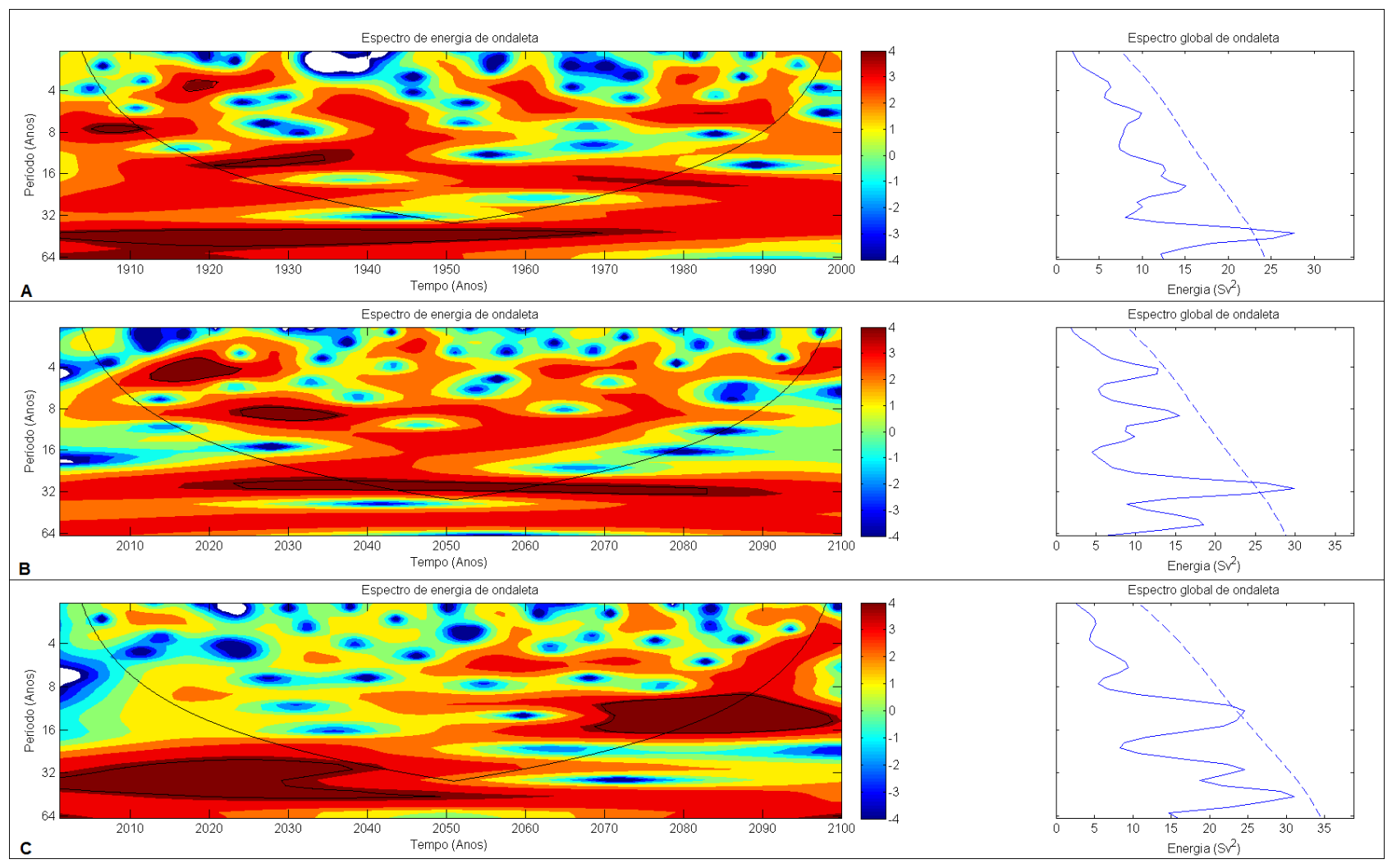

Figura 4 - Análise de ondaleta para o transporte de volume na seção $30^{\circ} \mathrm{S}$ nos cenários A) 20C3M, B) A1FI e C) B1. 
Os períodos de onda entre três e seis anos são dominantes nas seções $23^{\circ} \mathrm{S}$ e $25^{\circ} \mathrm{S}$ nos três cenários e ocorrem ao longo de todas as séries temporais, porém com magnitude variável. É importante notar que em todos os cenários, a seção $30^{\circ} \mathrm{S}$ exibe uma variabilidade completamente distinta das variabilidades apresentadas pelas seções $23^{\circ} \mathrm{S}$ e $25^{\circ} \mathrm{S}$. A variabilidade da seção $30^{\circ} \mathrm{S}$ é predominantemente maior que oito anos nos três cenários (Tabela II).

Considerando os períodos de maior energia, em todas as seções, a periodicidade da série de transporte de volume integrado apresentou uma diminuição nos cenários $\mathrm{A} 1 \mathrm{FI}$ e B1 quando comparados ao cenário 20C3M. O mesmo pode ser dito em relação ao fluxo de calor integrado. Por exemplo, na seção $25^{\circ} \mathrm{S}$ a principal periodicidade da série do transporte de volume no cenário 20C3M é seis anos, enquanto nos cenários A1FI e B1 apresentam periodicidade reduzida no valor de quatro anos (Tabela II).

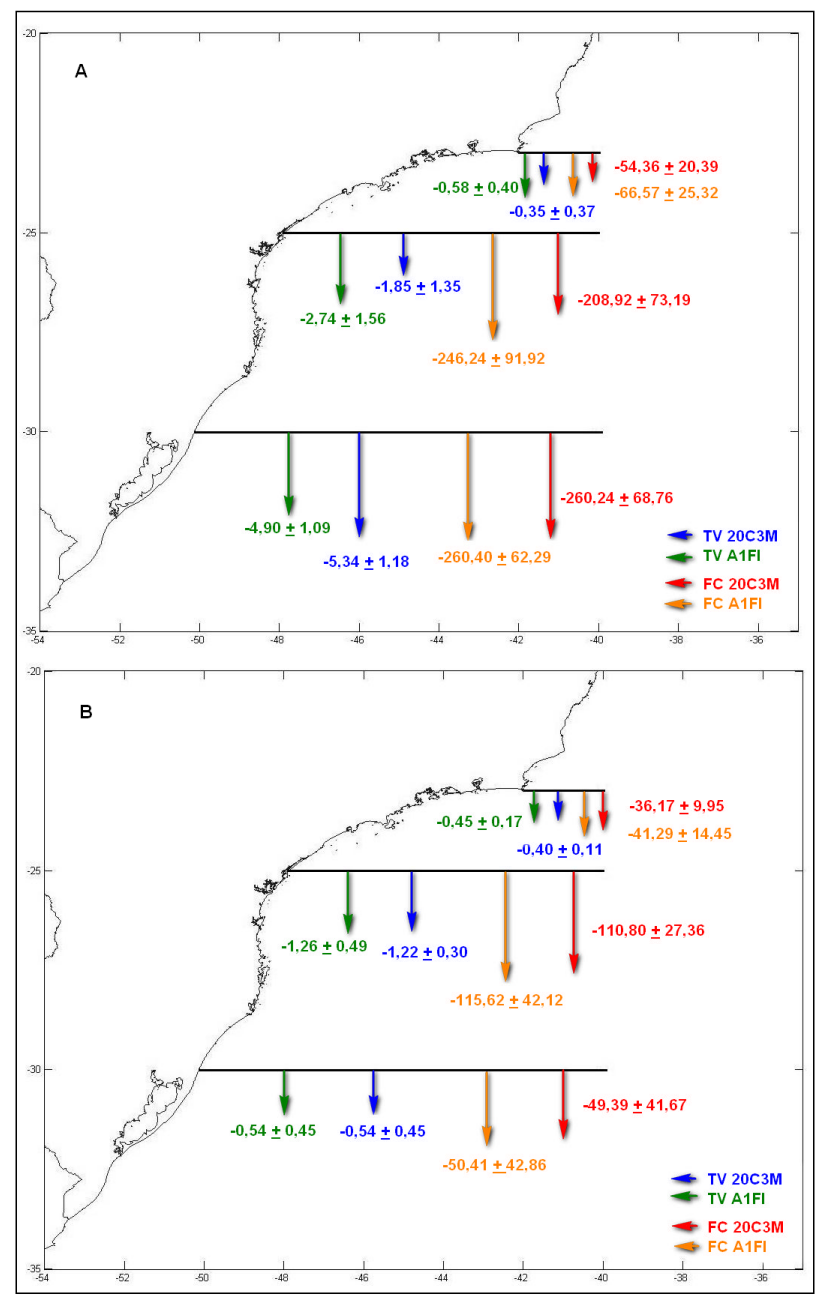

Figura 5 - Transportes de volume (TV em Sv) e fluxos advectivos de calor (FC em .10-3PW) integrados médios A) total e B) da AT no ano de 2017 em A1FI e entre 1901 e 2000 em 20C3M.

\section{Estudo dos Eventos mais Energéticos}

A partir dos resultados da Análise de Ondaletas, na banda interanual de dois à oito anos, foi identificado que em A1FI o ano de maior energia associada é 2017 e em B1, o ano 2064. O transporte de volume e o fluxo de calor integrados totais médios e os transportes e fluxos integrados das camadas correspondentes à AT, ACAS e AIA médios nestes anos foram comparados aos transportes e fluxos médios em 20C3M (Figuras $5,6,7$ e 8$)$.

Com exceção do transporte de volume médio da ACAS em $23^{\circ} S$ no cenário B1, o qual é em sentido norte em B1 e em sentido sul em 20C3M, os transportes de volume médios em A1FI em 2017, bem como em B1 em 2064, seguem o mesmo padrão dos transportes de volume médios em 20C3M. Nas três seções, o transporte de volume integrado total médio e os transportes de volume médios da AT e da ACAS de $A 1 F I, B 1$ e 20C3M são em sentido sul (valores negativos). Já o transporte de volume médio da AIA,

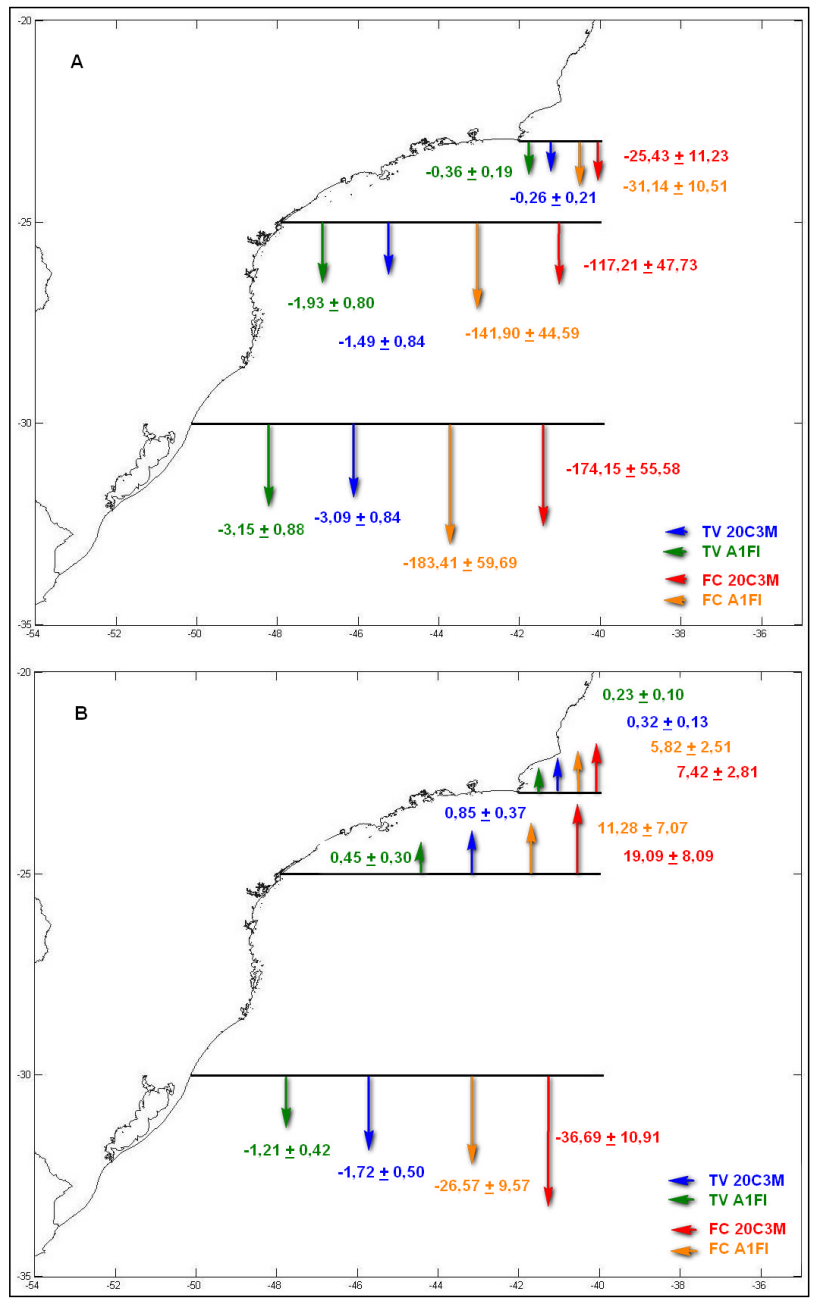

Figura 6 - Transportes de volume (TV em Sv) e fluxos advectivos de calor (FC em .10-3PW) integrados médios A) da ACAS e B) da AIA no ano de 2017 em A1FI e entre 1901 e 2000 em 20C3M. 


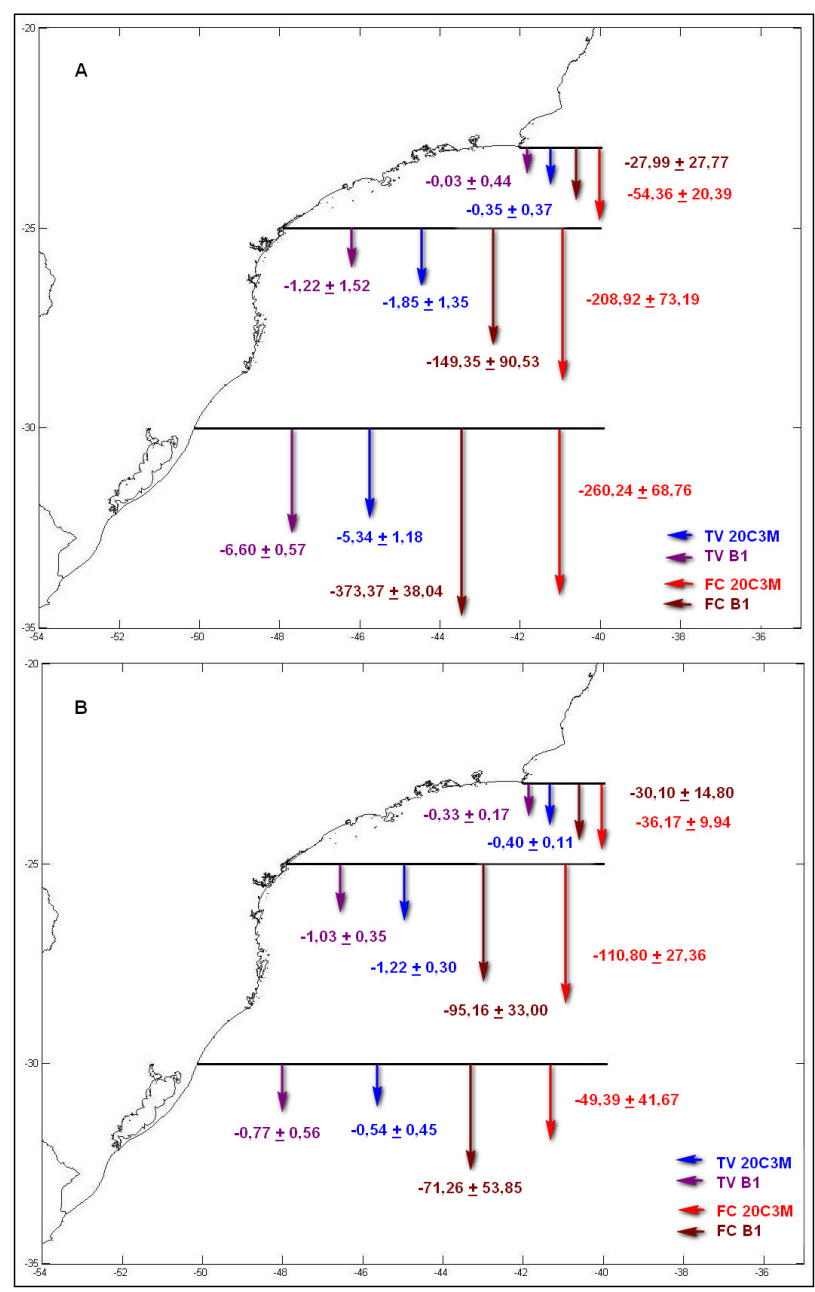

Figura 7 - Transportes de volume (TV em Sv) e fluxos advectivos de calor (FC em .10-3PW) integrados médios A) total e B) da AT no ano de 2064 em B1 e entre 1901 e 2000 em 20C3M.

nos três cenários, é para norte em $23^{\circ} \mathrm{S}$ e $25^{\circ} \mathrm{S}$. Já na seção $30^{\circ} \mathrm{S}$ o transporte médio da AIA assume valores negativos, indicando inversão de sentido.

Em A1FI, o transporte total do SCB médio é maior que o transporte médio em $20 \mathrm{C} 3 \mathrm{M}$ em $23^{\circ} \mathrm{S}$ e $25^{\circ} \mathrm{S}$, porém em $30^{\circ} \mathrm{S}$ o transporte em A1FI exibe uma diminuição em relação ao valor de 20C3M. O mesmo é observado em relação ao transporte médio da AT. Em relação à 20C3M, o transporte médio da ACAS é maior em $\mathrm{A} 1 \mathrm{FI}$ em todas as seções enquanto o transporte médio da AIA é menor em A1FI em todas as seções.

No cenário $B 1$, o transporte médio total do SCB é maior que o transporte médio em 20C3M somente em $30^{\circ} \mathrm{S}$. O transporte médio da AlA é menor em B1 em todas as seções quando comparado aos valores médios de 20C3M. Os transportes médios da AT e da ACAS são maiores que os transportes médios de 20C3M somente em $30^{\circ} \mathrm{S}$.

De maneira geral, os fluxos de calor médios totais e referentes a cada massa d'água seguem o

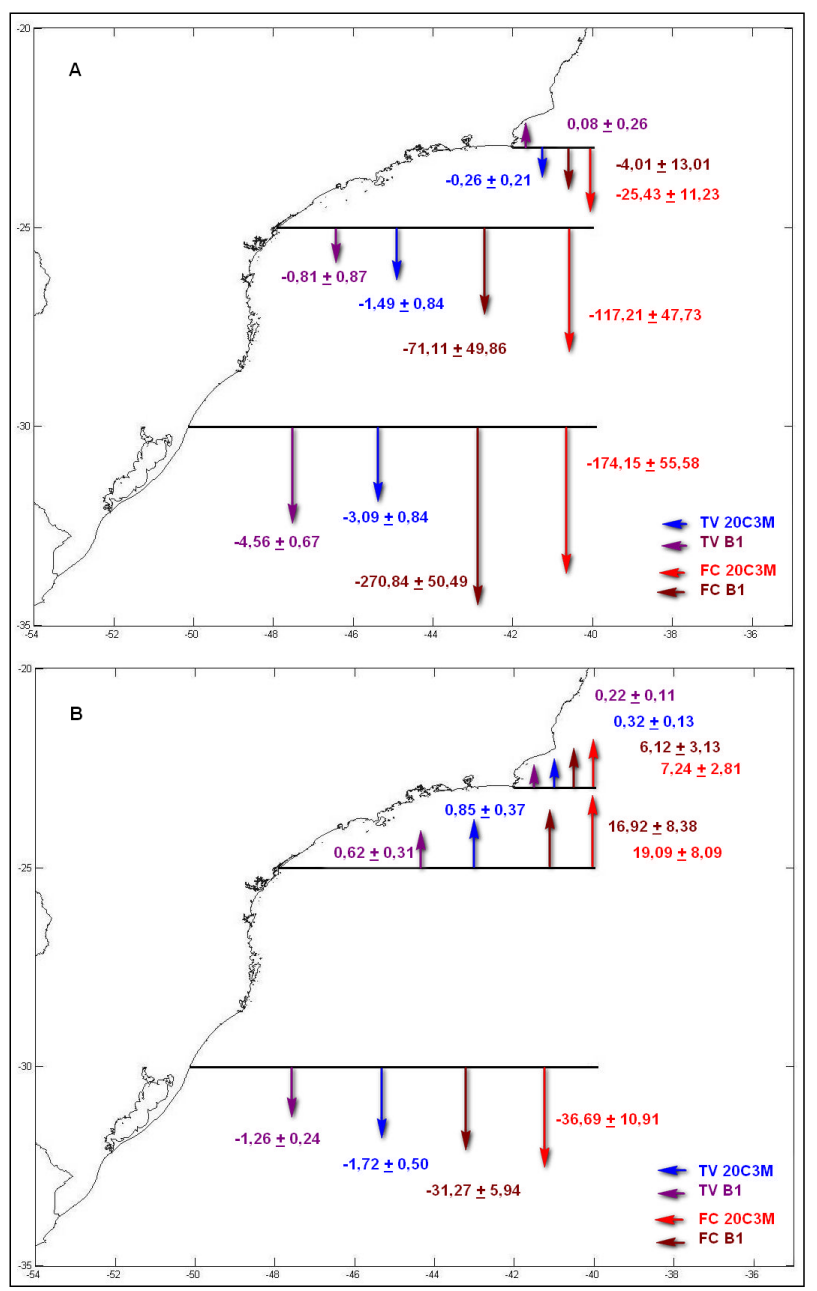

Figura 8 - Transportes de volume (TV em Sv) e fluxos advectivos de calor (FC em .10-3PW) integrados médios A) da ACAS e B) da AIA no ano de 2064 em B1 e entre 1901 e 2000 em 20C3M.

mesmo comportamento que os transportes de volume médios em relação à $20 \mathrm{C} 3 \mathrm{M}$, com exceção do observado na seção $30^{\circ} \mathrm{S}$ do cenário $\mathrm{A} 1 \mathrm{FI}$ para os transportes e fluxos médios totais e de AT e na seção $23^{\circ} \mathrm{S}$ do cenário $\mathrm{B} 1$ para os transportes e fluxos médios de ACAS.

\section{DISCUSSÃO}

A partir destes resultados pode ser claramente observado, em todos os cenários, o aumento do transporte do SCB à medida que a corrente flui para sul, conforme descrito inicialmente na literatura por Peterson \& Stramma (1991) e corroborado por diversos outros autores. Considerando a seção $23^{\circ} \mathrm{S}$ do cenário $20 \mathrm{C} 3 \mathrm{M}$, o transporte integrado médio é $-0,35 \mathrm{~Sv}( \pm 0,37)$. Neste mesmo cenário, o transporte de volume integrado médio aumenta para $-1,86 \mathrm{~Sv}( \pm$ $1,36)$ na seção $25^{\circ} \mathrm{S}$ e $-5,35 \mathrm{~Sv}( \pm 1,18)$ na seção $30^{\circ} \mathrm{S}$. 
Assim como o transporte de volume integrado, o fluxo de calor integrado, em todos os cenários, aumentou entre as seções $23^{\circ} \mathrm{S}, 2^{\circ} \mathrm{S}$ e $30^{\circ} \mathrm{S}$, esta última exibindo os maiores valores. Considerando a seção $23^{\circ} \mathrm{S}$ do cenário $20 \mathrm{C} 3 \mathrm{M}$, o fluxo de calor integrado médio é -54,36.10-3PW $( \pm 20,40.10-3)$. Neste mesmo cenário, o fluxo de calor integrado médio aumentou para -208,92.10-3PW $( \pm 73,20.10-3)$ na seção $25^{\circ} \mathrm{S}$ e $-260,24.10-3 P W( \pm 68,77.10-3)$ na seção $30^{\circ}$ S.

A análise das séries temporais do transporte de volume e fluxo de calor totais indica que na seção $23^{\circ} \mathrm{S}$ esses parâmetros apresentam valores positivos e negativos, indicando oscilação entre transportes ou fluxos no sentido norte e sul, respectivamente. Esse resultado indica uma maior variabilidade oceânica associada aos transportes nessa região, a qual pode estar associada ao posicionamento da bifurcação da célula de circulação de ACAS e da bifurcação da AT (Figura 1). O transporte de volume total também apresenta reversão em seu sentido na seção $25^{\circ} S$ nos três cenários e o fluxo de calor nesta mesma seção só não apresenta mudança em seu sentido no cenário $B 1$, no qual o fluxo de calor é sempre orientado para sul. A seção $30^{\circ} \mathrm{S}$, em todos os cenários, somente apresenta transporte de volume e fluxo de calor com sentido sul.

Nas séries temporais de transporte de volume e fluxo de calor é possível observar que oscilações de frequências mais altas são dominantes nas seções $23^{\circ} \mathrm{S}$ e $25^{\circ} \mathrm{S}$ nos três cenários, enquanto frequências mais baixas predominam nas séries temporais da seção $30^{\circ} \mathrm{S}$, comportamento este semelhante ao descrito por outros autores. Lumpkin \& Garzoli (2011) concluíram que o transporte de superfície associado à $\mathrm{CB}$ sofre variabilidade sazonal e interanual na série de dados analisados, entretanto os autores não observaram tendências à variabilidade de longo prazo na $\mathrm{CB}$, por exemplo, multidecadais, que só foram observadas na região da CBM.

Através da análise dos períodos de maior energia nas séries temporais de transporte de volume e fluxo de calor, observa-se nos cenários $\mathrm{A} 1 \mathrm{FI}$ e $\mathrm{B} 1$ o predomínio das frequências de variabilidade em períodos menores, comparativamente ao cenário 20C3M, indicando que o comportamento dos parâmetros oceanográficos do SCB é sensível às mudanças climáticas associadas aos cenários $\mathrm{A} 1 \mathrm{Fl}$ e B1.

Com os resultados da reanálise oceânica SODA, Vianna (2012) investigou as variabilidades interanuais do transporte de volume e do fluxo advectivo de calor em seções zonais em $23^{\circ} \mathrm{S}, 25^{\circ} \mathrm{S}$ e $30^{\circ} \mathrm{S}$ através da técnica de ondaletas, a qual revelou que os períodos de oscilação com maior energia estão concentrados entre dois e oito anos para as três seções, similarmente ao encontrado no presente trabalho para as seções $23^{\circ} \mathrm{S}$ e $25^{\circ} \mathrm{S}$. O autor sugere que este período de variabilidade poderia estar relacionado à ocorrência de eventos ENOS sobre o Pacífico Equatorial e que os transportes de volume e fluxos de calor seriam afetados por tais eventos através da alteração da profundidade limite entre as massas d'águas e da circulação oceânica do Atlântico Sul.

A partir da análise dos resultados dos eventos de 2017 no cenário $\mathrm{A} 1 \mathrm{FI}$ e 2064 no cenário B1, podemos observar que em $23^{\circ} \mathrm{S}$ e $25^{\circ} \mathrm{S}$, em todos os cenários, os transportes de volume e fluxo de calor médios de AIA são em sentido norte, correspondendo ao transporte de AIA em sentido oposto à CB nestas latitudes, conforme descrito por Stramma \& England (1999). Já na seção $30^{\circ} S$, o transporte de volume e o fluxo de calor médios dessa massa d'água são em sentido sul, já que esta seção se posiciona ao sul da bifurcação intermediária da $\mathrm{CCl}$.

Importante ressaltar que, nos dois cenários SRES, nos anos considerados para cada cenário (2017 para A1FI e 2064 para B1), há a diminuição do transporte de volume e do fluxo de calor médios de AIA nas três seções em relação à $20 \mathrm{C} 3 \mathrm{M}$. No evento de 2017, com exceção do transporte de volume médio total na seção $30^{\circ} \mathrm{S}$, os transportes de volume e os fluxos de calor médios totais, de AT e de ACAS aumentaram em A1FI em relação aos valores de 20C3M. No evento de 2064, excluindo-se o transporte de volume médio de ACAS em $23^{\circ} \mathrm{S}$, os transportes de volume e fluxo de calor médios totais, de AT e de ACAS diminuíram em B1 nas seções $23^{\circ} \mathrm{S}$ e $25^{\circ} \mathrm{S}$ e aumentaram em $30^{\circ} \mathrm{S}$, comparativamente à $20 \mathrm{C} 3 \mathrm{M}$.

\section{CONCLUSÕES}

No presente trabalho foi realizado um estudo sobre os padrões de variabilidade do transporte de volume e fluxo advectivo de calor do SCB e as possíveis modificações que podem ocorrer nestes parâmetros quando o SCB estiver sob influência de cenários futuros de mudanças climáticas.

De acordo com os resultados obtidos no presente trabalho, é possível observar que de fato o SCB, nas seções avaliadas, exibe alterações nos valores de fluxo de calor e transporte de volume, bem como na variabilidade destes parâmetros, quando submetidos aos cenários de emissão A1FI e B1.

É observado um aumento nos transportes de volume médios totais em todas as seções nos cenários $\mathrm{A} 1 \mathrm{FI}$ e $\mathrm{B} 1$, comparativamente ao cenário 20C3M. Excluindo o fluxo de calor médio da seção $23^{\circ} \mathrm{S}$ do cenário $\mathrm{A} 1 \mathrm{FI}$, os fluxos de calor médios totais das outras seções e cenários também apresentaram aumento em relação aos fluxos de calor médios totais em 20C3M. 
Considerando os transportes de volume médios e os fluxos de calor médios de AT e AIA, em todas as seções nos cenários $A 1 \mathrm{FI}$ e $B 1$ esses valores se comportam semelhantemente. É observado o aumento dos transportes de volume médios e dos fluxos de calor médios em AT e redução dos transportes de volume médios e dos fluxos de calor médios em AIA, comparativamente às mesmas massas d'água no cenário 20C3M. Já a ACAS apresenta um comportamento distinto entre os cenários. $\mathrm{Em} 23^{\circ} \mathrm{S}$ há uma redução, em $25^{\circ}$ S há redução em $\mathrm{A} 1 \mathrm{FI}$ e aumento em $\mathrm{B} 1$ e em $30^{\circ} \mathrm{S}$ há um aumento dos transportes de volume médios e dos fluxos de calor médios em relação aos valores médios da ACAS no cenário $20 \mathrm{C} 3 \mathrm{M}$.

Os resultados da Análise de Ondaletas também indicam diferenças na variabilidade das séries temporais utilizadas. A variabilidade em escalas temporais mais longas (maiores que oito anos) é predominante nas séries temporais de transporte de volume e fluxo de calor totais na seção $30^{\circ} \mathrm{S}$. Nas seções $23^{\circ} \mathrm{S}$ e $25^{\circ} \mathrm{S}$ predomina a variabilidade em escalas temporais mais curtas, entre três e seis anos. Além disso, é observado o deslocamento da variabilidade das séries temporais de transporte de volume e fluxo de calor totais para frequências mais altas quando submetidos aos cenários de mudanças climáticas $\mathrm{A} 1 \mathrm{FI}$ e $\mathrm{B} 1$.

Considerando que os resultados encontrados apontam para mudanças expressivas na variabilidade dos parâmetros estudados, cabe ressaltar que estudos sobre os possíveis processos atmosféricos ou oceânicos remotos que resultariam neste tipo de comportamento seriam de grande importância à compreensão destas alterações.

\section{REFERÊNCIAS}

Assad, L.P.F. 2006. Influência do campo de vento anômalo tipo ENSO na dinâmica do Atlântico Sul. Tese de Doutorado. Programa de Engenharia Civil - COPPE/UFRJ. 187 p.

Campos, E.J.D.; Gonçalves, J.E. \& Ikeda, Y. 1995. Water mass structure and geostrophic circulation in the South Brazil Bight - Summer of 1991. J. Geophys. Res. 100(9): 18537-18550.

Delworth, T.L.; Broccoli, A.J.; Rosati, A.; Stouffer, R.J.; Balaji, V.; Beesley, J.T.; Cooke, W.F. 2006. GFDL's CM2 global coupled climate models. Part I: formulation and simulation characteristics. J. Climate 19(1): 643-674.

Evans, D.L. \& Signorini, S.R. 1985. Vertical structure of the Brazil Current. Nature 315(6014): 48-50.

Evans, D.L; Signorini, S.R. \& Miranda, L.B. 1983. A note on the transport of the Brazil Current. J. Phys. Oceanogr. 13(9): 1732-1738.
Garzoli, S.L. 1993. Geostrophic velocity and transport variability in the Brazil-Malvinas Confluence. Deep-Sea Res. 40(7): 1379-1403.

Garzoli, S.L. \& Baringer, M.O. 2007. Meridional heat transport determined with expandable bathythermographs - Part II: South Atlantic transport. Deep-Sea Res. 54(8): 1402-1420.

Garzoli, S.L. \& Giulivi, C. 1994. What forces the variability of the southwestern Atlantic boundary currents? Deep-Sea Res. 41(10): 1527-1550.

Godói, S.S. 2005. Dinâmica quase-geostrófica do Sistema Corrente do Brasil no embaiamento de São Paulo $\left(23,5^{\circ}-27^{\circ} \mathrm{S}\right)$. Tese de Doutorado. Instituto Oceanográfico da Universidade de São Paulo - IOUSP. 133 p.

Gordon, A.L. \& Greengrove, C.L. 1986. Geostrophic circulation of the Brazil-Falkland confluence. Deep-Sea Res. 33(5): 573-585.

Intergovernmental Panel On Climate Change (IPCC). 2000. Special Report Emissions Scenarios Summary for Policymakers. Cambridge University Press, Cambridge, $21 \mathrm{p}$.

Kushnir, Y.; Robinson, W.A.; Blade, I.; Hall, N.M.J.; Peng, S. \& Sutton, R. 2002. Atmospheric GCM response to extratropical SST anomalies: synthesis and evaluation. J. Climate 15(1): 2233 - 2256.

Lau, K.M. \& Weng, H. 1995. Climate signal detection using wavelet transform: how to make a time series sing. B. Am. Meteorol. Soc. 76(12): 2391-2402.

Lumpkin, R. \& Garzoli, S. 2011. Interannual to decadal changes in the western South Atlantic's surface circulation. J. Geophys. Res. 116(1): 105-115.

Marengo, J.A. 2007. Caracterização do clima no século XX e cenários climáticos no Brasil e na América do Sul para o século XXI derivados dos modelos globais do IPCC. Ministério do Meio Ambiente, São Paulo, 181 p.

Matano, R.P.; Schlax, M.G. \& Chelton, D.B. 1993. Seasonal variability in the Southwestern Atlantic. J. Geophys. Res. 98(10): 27-35.

Mémery, L.; Arhan, M.; Alvarez-Salgado, X.A.; Messias, M.J.; Mercier, H.; Castro, C.G. \& Rios, A.F. 2000. The water masses along the western boundary of the south and equatorial Atlantic. Prog. Oceanogr. 47(1): 69-98.

Morlet, J. 1983. Sampling theory and wave propagation. In: Chen, C.H. (ed.) Acoustic signal/image processing and recognition. Springer-Verlag. 233-261pp.

Müller, T.J.; Ikeda, Y.; Zangenberg, N. \& Nonato, L.V. 1998. Direct measurements of the western boundary currents between $20^{\circ} \mathrm{S}$ and $28^{\circ} \mathrm{S}$. J. Geophys. Res. 103(3): 5429 - 5543.

Olson, D.B.; Podesta, G.P.; Evans, R.H. \& Brown, O.B. 1988. Temporal variations in the separation 
of Brazil and Malvinas currents. Deep-Sea Res. 35(12): 1971-1990.

Peterson, R.G. \& Stramma, L. 1991. Upper-level circulation in the South Atlantic Ocean. Prog. Oceanogr. 26(1): 1-73.

Schott, F.A.; Dengler, M.; Zantopp, R.; Stramma, L.; Fischer, J. \& Brandt, P. 2005. The shallow and deep western boundary circulation of the South Atlantic at $5-11^{\circ} \mathrm{S}$. J. Phys. Oceanogr. 35(1): 2031-2053.

Silveira, I.C.A. 2007. O Sistema Corrente do Brasil na Bacia de Campos, RJ. Tese de Livre Docência. Instituto Oceanográfico da Universidade de São Paulo- IOUSP. 160 p.

Soutelino, R.G. 2008. A origem da Corrente do Brasil. Dissertação de Mestrado. Instituto Oceanográfico da Universidade de São Paulo-IOUSP.101 p.

Stramma, L. 1989. The Brazil Current transport south of $23^{\circ} \mathrm{S}$. Deep-Sea Res. 356(4): 639-646.

Stramma, L. \& England, M. 1999. On the water masses and mean circulation of the South Atlantic ocean. J. Geophys. Res. 104(C9): 20863-20883.

Stramma, L.; Ikeda, Y. \& Peterson, R.G. 1990. Geostrophic transport in the Brazil Current region north of $20^{\circ} \mathrm{S}$. Deep-Sea Res. 37(12): 1875-1886.
Stramma, L.; Rhein, M.; Brandt, P.; Dengler, M.; Böning, C. \& Walter, M. 2005. Upper ocean circulation in the western tropical Atlantic in boreal fall 2000. Deep-Sea Res. 52(2): 221-240.

Stramma, L. \& Schott, F. 1999. The mean flow field of the tropical Atlantic Ocean. Deep-Sea Res. 46(1): 279-304.

Torrence, C. \& Compo, G.P. 1998. A Practical guide to Wavelet Analysis. B. Am. Meteorol. Soc. 79(1): 61-78.

Vianna, V.P.D. 2012. Variabilidades interanuais do transporte de volume e fluxo advectivo de calor sobre a plataforma continental brasileira entre as latitudes de $23^{\circ} \mathrm{S}$ e $30^{\circ} \mathrm{S}$. Dissertação de mestrado. Programa de Engenharia Civil - COPPE/UFRJ. $71 \mathrm{p}$.

Wainer, I. \& Venegas, S.A. 2002. South Atlantic multidecadal variability in the climate system model. J. Climate 15(1): 1408-1420.

Submetido: Julho/2013

Revisado: Novembro/2014

Aceito: Janeiro/2016 